\title{
The impacts of changing transport and precipitation on pollutant distributions in a future climate
}

\author{
Yuanyuan Fang, ${ }^{1,2}$ Arlene M. Fiore, ${ }^{2}$ Larry W. Horowitz, ${ }^{1,2}$ Anand Gnanadesikan, ${ }^{1,2,3}$ \\ Isaac Held, ${ }^{1,2}$ Gang Chen, ${ }^{4}$ Gabriel Vecchi, ${ }^{2}$ and Hiram Levy ${ }^{2}$ \\ Received 15 January 2011; revised 18 May 2011; accepted 13 June 2011; published 17 September 2011.
}

[1] Air pollution (ozone and particulate matter in surface air) is strongly linked to synoptic weather and thus is likely sensitive to climate change. In order to isolate the responses of air pollutant transport and wet removal to a warming climate, we examine a simple carbon monoxide-like (CO) tracer (COt) and a soluble version (SAt), both with the 2001 CO emissions, in simulations with the Geophysical Fluid Dynamics Laboratory chemistry-climate model (AM3) for present (1981-2000) and future (2081-2100) climates. In 2081-2100, projected reductions in lower-tropospheric ventilation and wet deposition exacerbate surface air pollution as evidenced by higher surface COt and SAt concentrations. However, the average horizontal general circulation patterns in 2081-2100 are similar to 1981-2000, so the spatial distribution of COt changes little. Precipitation is an important factor controlling soluble pollutant wet removal, but the total global precipitation change alone does not necessarily indicate the sign of the soluble pollutant response to climate change. Over certain latitudinal bands, however, the annual wet deposition change can be explained mainly by the simulated changes in large-scale (LS) precipitation. In regions such as North America, differences in the seasonality of LS precipitation and tracer burdens contribute to an apparent inconsistency of changes in annual wet deposition versus annual precipitation. As a step toward an ultimate goal of developing a simple index that can be applied to infer changes in soluble pollutants directly from changes in precipitation fields as projected by physical climate models, we explore here a "Diagnosed Precipitation Impact" (DPI) index. This index captures the sign and magnitude (within 50\%) of the relative annual mean changes in the global wet deposition of the soluble pollutant. DPI can only be usefully applied in climate models in which LS precipitation dominates wet deposition and horizontal transport patterns change little as climate warms. Our findings support the need for tighter emission regulations, for both soluble and insoluble pollutants, to obtain a desired level of air quality as climate warms.

Citation: Fang, Y., A. M. Fiore, L. W. Horowitz, A. Gnanadesikan, I. Held, G. Chen, G. Vecchi, and H. Levy (2011), The impacts of changing transport and precipitation on pollutant distributions in a future climate, J. Geophys. Res., 116, D18303, doi:10.1029/2011JD015642.

\section{Introduction}

[2] Air quality is influenced by meteorological conditions and thus could be sensitive to climate change [e.g., Denman et al., 2007]. Over the next century, models project significant changes in global and regional climate [e.g., Christensen et al., 2007; Meehl et al., 2007], including increases in temperature, changes in the hydrological cycle, alterations in

\footnotetext{
${ }^{1}$ Atmospheric and Oceanic Sciences Program, Princeton University, Princeton, New Jersey, USA.

${ }^{2}$ Geophysical Fluid Dynamics Laboratory, National Oceanic and Atmospheric Administration, Princeton, New Jersey, USA.

${ }^{3}$ Now at Department of Earth and Planetary Science, Johns Hopkins University, Baltimore, Maryland, USA.

${ }^{4}$ Department of Earth and Atmospheric Sciences, Cornell University, Ithaca, New York, USA.

Copyright 2011 by the American Geophysical Union. 0148-0227/11/2011JD015642
}

global and regional circulation patterns (e.g., poleward expansion of the Hadley cell, reduced tropical convective mass fluxes and reduced midlatitude cyclone frequency). These changes are expected to affect pollutant transport processes, natural pollutant precursor emissions that depend strongly on meteorology (lightning $\mathrm{NO}_{\mathrm{x}}$, biogenic emissions), and the rates of chemical reactions. Estimating the climate change impact on air quality requires a good understanding of each of these processes.

[3] Most General Circulation Model (GCM) and Chemical Transport Model (CTM) studies of the impact of climate change on air pollutants focus on ozone $\left(\mathrm{O}_{3}\right)$ and particulate matter (PM) because these two species are of most concern for human health and directly affect both air quality and atmospheric radiative forcing [e.g., Jacob and Winner, 2009]. Models show consistently that as a result of 21 st-century climate change, background $\mathrm{O}_{3}$ in the lower troposphere (where $\mathrm{O}_{3}$ loss by reacting with water vapor is dominant) will 
decrease while surface $\mathrm{O}_{3}$ over polluted regions at northern midlatitudes will increase (+1-10 ppbv) [ Wu et al., 2008a, 2008b; Lin et al., 2008; Nolte et al., 2008; Weaver et al., 2009]. For PM, models predict significant changes $( \pm 0.1-$ $1 \mu \mathrm{g} \mathrm{m}^{-3}$ ) but neither the sign nor the magnitude is consistent across models [Jacob and Winner, 2009]. The uncertainty regarding the impact of climate on particulate matter reflects the complexity of the dependence of its components on meteorological variables, and the key role of precipitation in modulating PM sinks [Racherla and Adams, 2006; Tagaris et al., 2007; Avise et al., 2009; Pye et al., 2009; Dawson et al., 2007]. Although Racherla and Adams [2006] showed that a lower PM burden corresponds to an increase in global precipitation in a future climate, Pye et al. [2009] indicated that changes in precipitation are not always the governing factor for PM concentrations. Jacob and Winner [2009] argued that precipitation frequency is likely the dominant factor determining PM concentration changes. Such disparate results in the literature motivate our investigation into the impact of changing precipitation on soluble pollutants in a warmer climate.

[4] To isolate the roles of transport and precipitation, processes affecting many air pollutants, idealized atmospheric tracers can be used to represent air pollutants in a climate model. Previous studies have applied atmospheric tracers in GCMs to study the impact of transport changes under climate change. For example, Holzer and Boer [2001] analyzed tracers emitted from temporally constant localized surface sources. They find that interhemispheric exchange times, mixing times, and mean transit times all increase under global warming by about $10 \%$ from 1990 to 2000 to 2090-2100, but they consider only advection and diffusion and neglect wet deposition and convection. Furthermore, their tracers have localized (rather than distributed) sources, permitting the identification of transport pathways from specific locations while precluding examination of the impact of spatial patterns in precipitation and ventilation changes over polluted regions. Rind et al. [2001] examined changes in the distributions of long-lived tracers (such as $\mathrm{CO}_{2}$ and CFCs) in a doubled- $\mathrm{CO}_{2}$ climate and found a $30 \%$ increase in troposphere-to-stratosphere transport and a decrease in surface tracers because of enhanced convection. Mickley et al. [2004] incorporated black carbon (BC) and CO-like tracers of fossil fuel emissions in a GCM and found that the severity and duration of summertime regional pollution episodes in the Midwest and northeastern United States increase significantly relative to the present because of decreased frequency of migratory cyclones. So far, the impacts of projected precipitation changes on the burdens of soluble pollutants, such as oxidized nitrogen, sulfate and nitrate aerosols, have not been isolated from other climate impacts (e.g., chemical evolution, emission changes).

[5] In order to investigate how pollutant distributions respond to changing transport and precipitation in a warmer climate, we apply idealized tracers (with insoluble and soluble versions) in a global chemistry-climate coupled model (Atmospheric Model version 3, AM3, developed by the Geophysical Fluid Dynamics Laboratory (GFDL)) [Donner et al., 2011]. In section 2, we describe our model, including the model parameterizations most relevant to this study and the experiments conducted. Changes in the future distributions of soluble and insoluble tracers are described and compared in section 3. Section 4 discusses the circulation changes that are responsible for redistributing the insoluble tracer in a warmer climate. Section 5 shows the impact of precipitation changes on soluble tracer distributions. Conclusions are given in section 6 .

\section{Methods}

\subsection{Model Description}

[6] We use the GFDL AM3 model [Donner et al., 2011] to examine the impact of climate change on tracer distributions. AM3 uses a finite-volume dynamical core similar to that used in CM2.1 [Delworth et al., 2006] but implements on a cubed-sphere grid [Putman and Lin, 2007]. The Earth is represented as a cube with six rectangular faces and there is no singularity associated with the north and south poles as with the latitude-longitude representation, avoiding the need for polar filtering. The model horizontal resolution is C48 (48 $\times 48$ cells per face); the size of the grid cell varies from $\sim 163 \mathrm{~km}$ (at the 6 corners of the cubed sphere) to $231 \mathrm{~km}$ (near the center of each face). The model used in our simulations has 48 vertical levels, with the top level centered at $1.7 \mathrm{~Pa}(\sim 75 \mathrm{~km})$.

[7] Aerosols and gases are transported in the model by advection, convection, and eddy diffusion by turbulence with full stratospheric [Austin and Wilson, 2006] and tropospheric [Horowitz et al., 2003] chemistry, as described in detail by Donner et al. [2011]. Aerosol-cloud interactions are also included in AM3 model simulations [Donner et al., 2011]. Most pertinent to our study is the wet deposition parameterization, which we describe briefly here. Wet deposition includes in-cloud and below-cloud scavenging by large-scale and convective clouds. The wet deposition flux $(W)$ is directly proportional to the local concentration $(C)$, given by $W=\Gamma \cdot C$, where $\Gamma$ is the wet scavenging coefficient. In-cloud scavenging of aerosols is calculated following the work of Giorgi and Chameides [1985]. The in-cloud scavenging coefficient is:

$$
\Gamma_{\text {in }}=1-\exp (-\beta \cdot f), \beta=\frac{P_{\text {rain }}^{k+1}-P_{\text {rain }}^{k}+P_{\text {snow }}^{k+1}-P_{\text {snow }}^{k}}{\Delta p \cdot g^{-1} \cdot x_{\text {liq }}} ;
$$

where $f$ is the scavenging factor, $P^{k}$ is the precipitation flux through the top of layer $\mathrm{k}, P^{k+1}$ is the precipitation flux through the bottom of layer k (top of layer k +1 ) (thus, $P^{k+1}$ $P^{k}$ is the precipitation generated in layer $\mathrm{k}$ ), $\Delta p$ is the pressure thickness of the model layer $\mathrm{k}$ and $g$ is the gravitational acceleration. The liquid water content $x_{\text {liq }}\left(=\frac{\text { Cloud water }(\mathrm{kg})}{\text { air mass }(\mathrm{kg})}\right)$ is calculated by the large-scale cloud and convective parameterizations. The fraction of aerosol incorporated in the cloud condensate, $f$, is prescribed. For sulfate, it is 0.2 in large-scale clouds and 0.5 in convective clouds (note that these scavenging factors differ from those used by Donner et al. [2011]). These fractions qualitatively correspond to the relative solubility and cloud drop nucleation properties of the aerosols, but the quantitative values are selected (globally) to provide a reasonable simulation of the global mean and regional patterns of aerosol optical depth (AOD) [Donner et al., 2011]. In the case of convective precipitation, wet deposition is only computed within the updraft plume. In our simulations, in-cloud scavenging of sulfate aerosols does not depend on the size of the droplet, the size of sulfate aerosols, 


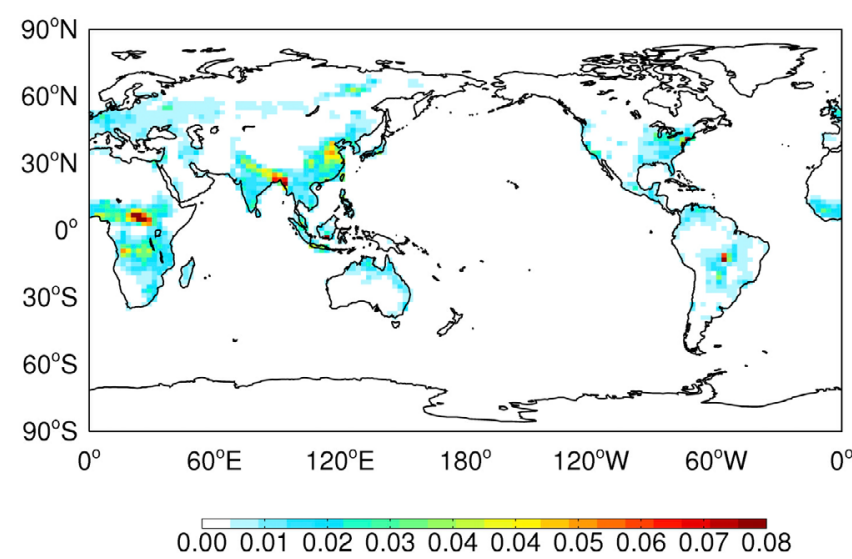

Figure 1. Annual mean COt emissions (units are $10^{-1} \mathrm{~mol} /$ $\mathrm{m}^{2} / \mathrm{d}$, including both anthropogenic and biomass burning emissions (HTAP, 2007, http://www.htap.org).

or the type of precipitation (rain or snow). Below-cloud washout is only considered for large-scale precipitation and is parameterized as by Li et al. [2008] for aerosols with the below cloud scavenging coefficient $\left(\Gamma_{b c}\right)$ calculated as $\Gamma_{b c}=\frac{3}{4}\left(\frac{P_{\text {rain }} \cdot \alpha_{\text {rain }}}{R_{\text {rain }} \cdot \rho_{H_{2} O} O}+\frac{P_{\text {snow }} \cdot \alpha_{\text {snow }}}{R_{\text {snow }} \cdot \rho_{\text {snow }}}\right)$, where $P_{\text {rain }}$ and $P_{\text {snow }}$ are the precipitation fluxes, $\alpha$ is the efficiency with which aerosols are collected by raindrops and snow with $\alpha_{\text {rain }}=0.001$ and $\alpha_{\text {snow }}=0.001, \mathrm{R}$ is the radius of precipitation droplets with $R_{\text {rain }}=0.001 \mathrm{~m}$ and $R_{\text {snow }}=0.001 \mathrm{~m}, \rho$ is density with $\rho_{\mathrm{H}_{2} \mathrm{O}}=$ $1000 \mathrm{kgm}^{-3}$ and $\rho_{\text {snow }}=500 \mathrm{kgm}^{-3}$.

\subsection{Experiments and Tracers}

[8] We conduct a pair of idealized simulations designed to detect climate change signals rather than model internal variability. For the present-day climate (denoted as "19812000 "), we use a monthly 20 year mean annually invariant climatology of observed sea surface temperature and sea ice from the Hadley Center to drive our AM3 simulation. For the future climate (referred to as "2081-2100"), we add the 20 year mean monthly anomalies of sea surface temperature and sea ice extent (calculated from a 19 model IPCC AR4 A1B scenario ensemble mean; these models include CSIRO-Mk3.5 [Gordon et al., 2002], INGV-ECHAM4 [Gualdi et al., 2006] and the models in Table 1 of Vecchi and Soden [2007], except models number 10, 11, 12, 9 and 20) to the present-day observed climatological values. Both simulations are run for 21 years with the first year as spin-up. Emissions of aerosols and trace gases in both simulations are kept at 1990 levels. Long-lived greenhouse gas concentrations $\left(\mathrm{CO}_{2}, \mathrm{~N}_{2} \mathrm{O}\right.$ and $\left.\mathrm{CFCs}\right)$ are set to the 1990 values in the present-day simulation and to the $2090 \mathrm{~A} 1 \mathrm{~B}$ values in the future climate run. $\mathrm{CH}_{4}$ is set to the 1990 levels for tropospheric chemistry calculations and the present-day radiation calculations, but to the A1B 2090 level for the radiation calculation in the future climate run, thus distinguishing between the direct radiative impact of $\mathrm{CH}_{4}$ forcing on the circulation from its indirect chemical impacts (changing radiatively active tracers like $\mathrm{O}_{3}$ ). These settings allow us to study the effect of climate change on pollutants separately from the role of changes in anthropogenic pollutant emissions. The AM3 simulated global surface temperature increases by
$2.7 \mathrm{~K}$ and global precipitation increases by $6 \%$ from $1981-$ 2000 to 2081-2100, consistent with the IPCC AR4 report $(2.8 \mathrm{~K}$ and $6 \%$ increases of surface temperature and precipitation in the AR4 model ensemble mean) [Meehl et al., 2007].

[9] Although our simulations include full chemistry as described above, we introduce two sets of idealized tracers into our simulations and focus exclusively on these tracers in this paper to clearly diagnose the impact of circulation and precipitation changes in 2081-2100 on pollutant distributions. First is a passive tracer, COt, which decays exponentially with a $25 \mathrm{~d}$ lifetime. The emissions of $\mathrm{COt}$ (Figure 1) mimic CO emissions in 2001, including anthropogenic emissions from the RETRO project [Schultz and Rast, 2007; http://www.retro.enes.org] and biomass burning emissions from GFED version2 [van der Werf et al., 2006]. Second, a soluble tracer, SAt, follows the same emission and decays as COt, but is subjected to additional removal by wet deposition as for sulfate aerosols (section 2.1) (note, dry deposition is not considered). The effective global atmospheric lifetime of SAt ranges from 4 to $6 \mathrm{~d}$ depending on season. The application of these tracers is adapted from the diagnostic tracer experiments (TP) of the Task Force on Hemispheric Transport of Atmospheric Pollutants (HTAP, 2007, http://www.htap.org). The total anthropogenic and biomass burning $\mathrm{CO}$ emissions are about $1000 \mathrm{Tg} \mathrm{CO} \mathrm{yr}^{-1}$. Our paper focuses on the discussion of these two tracers, but we also include other tracers (COt12 and SAt12, similar to COt and SAt, but with a $12 \mathrm{~d}$ lifetime). While we examine here tracers with 25 and $12 \mathrm{~d}$ lifetimes, and their soluble counterparts (with 4-6 and 3-4 d lifetimes, respectively), we do not exhaustively address all timescales associated with pollution transport.

[10] The major advantages of our approach are the following: 1. the emissions of these tracers follow the surface emissions of $\mathrm{CO}$, including both anthropogenic and biomass burning emissions, and their lifetimes are close to those of real pollutants, such as $\mathrm{CO}(\mathrm{COt})$ and sulfate aerosols (SAt); 2 . the application of this pair of tracers, with and without wet deposition, helps us to isolate the impact of precipitation in a future climate; 3 . we use two 20 year simulations driven by annually invariant sea surface temperature and sea ice to maximize the detection of a climate change signal relative to the internal model variability; 4. there are already a host of HTAP TP model simulations for present-day climate, so this study could be repeated fairly easily by other models to build a multimodel ensemble.

\section{The Redistribution of Insoluble and Soluble Pollutants in a Warmer Climate}

[11] Figure 2 shows the zonal mean distributions of the COt and SAt tracers, respectively, in 1981-2000 and the changes from 1981-2000 to 2081-2100. During 19812000, both COt and SAt have the largest concentrations at the surface near the tropics and over the northern midlatitudes, reflecting the emissions distribution (Figure 1). Wet deposition is the major sink of SAt, accounting for $70 \%$ of its total loss. Because of this additional sink compared to COt, SAt has a much shorter lifetime $(5 \mathrm{~d})$ than COt and its concentration decreases much more rapidly away from its sources. The mean tracer concentrations in the lower tro- 
a

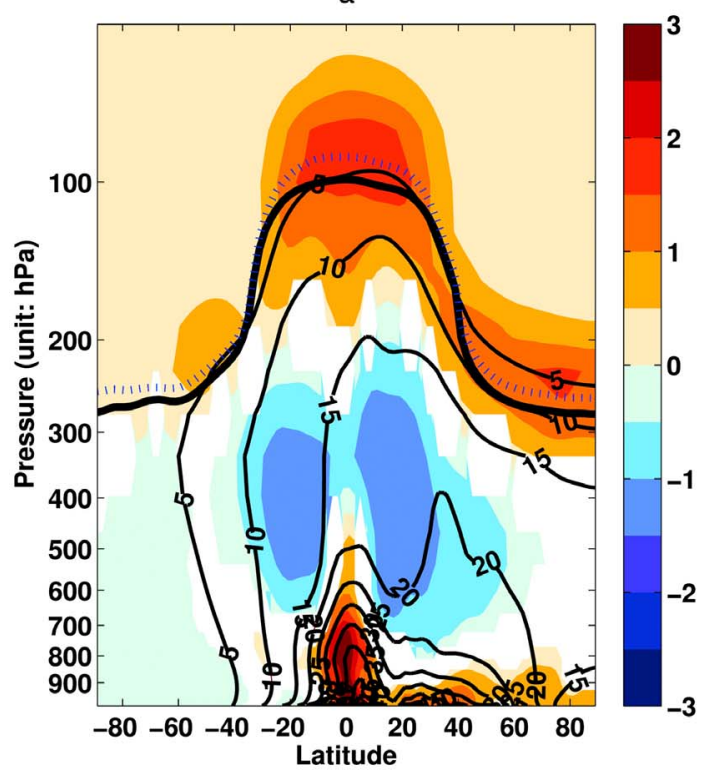

b

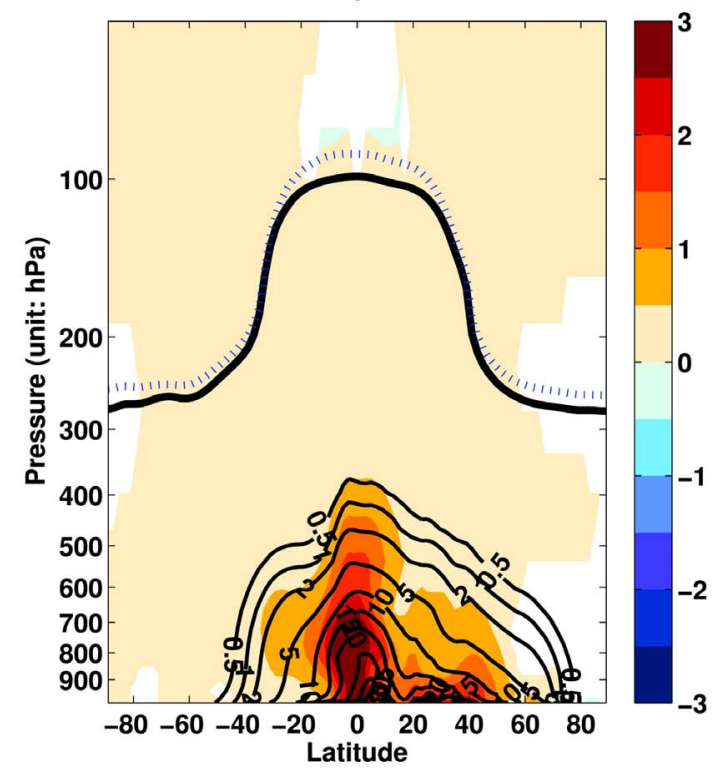

Figure 2. The 20 year average zonal mean distribution of idealized tracer (unit: ppbv) during 1981-2000 (black solid contour) and the changes of that tracer from 1981-2000 to 2081-2100 (color shaded) with respect to vertical coordinates of pressure. (a) COt tracer and (b) SAt tracer. Blue dashed and dotted lines show the tropopause location during 1981-2000 and 2081-2100, respectively (as identified by Reichler et al. [2003], based on the World Meteorological Organization (WMO) lapse-rate criterion); only changes significant at the $95 \%$ confidence level assessed by $t$ test are shown.

posphere (below $500 \mathrm{hPa}$ ) and in the free troposphere (above $500 \mathrm{hPa}$ ) are 19 and $13 \mathrm{ppbv}$, respectively, for COt, versus 7.4 and 0.3 ppbv for SAt in 1981-2000.

[12] Any redistribution of COt in the 2081-2100 simulation reflects only circulation changes in a future climate. At the surface, COt concentrations increase by up to $6 \mathrm{ppbv}$ in the tropics and up to $1.5 \mathrm{ppbv}$ at northern hemispheric midlatitudes (with relative changes from 2 to $7 \%$ ). In the free troposphere, COt concentrations decrease with a maximum reduction of up to $2 \mathrm{ppbv}(-2$ to $-12 \%$ at $400 \mathrm{hPa}$ ). Near the tropopause, a large increase in the COt concentration (with a maximum of 2 ppbv) occurs. COt tracer generally decreases in the southern hemisphere. Although circulation changes redistribute COt, the global tropospheric burden remains the same from 1981-2000 to 2081-2100 because of the fixed $25 \mathrm{~d}$ lifetime and fixed emissions. Similar patterns emerge for the $12 \mathrm{~d}$ lifetime insoluble tracer.

[13] As will be shown in section 5, the future changes in tropospheric SAt distribution differ strongly from that of $\mathrm{COt}$ because it undergoes wet deposition. SAt surface concentration increases both in the tropics and at the northern hemispheric midlatitudes, similar to COt, but with a greater relative change (above 10\%). The increased surface concentrations of SAt and COt suggest that a warmer climate will contribute to degraded air quality in the future. In the free troposphere and the southern hemisphere (where COt concentration decreases), the SAt concentration increases. The tropospheric SAt burden increases from 17 to $19 \mathrm{Gg}(+12 \%)$ in the future, indicating a $12 \%$ increase of lifetime from 1981-2000 to 2081-2100 (as emissions are identical). Since wet deposition is the only difference between the two tracers, the different responses between SAt and COt result solely from future changes in precipitation. We will discuss next the causes of the redistribution of COt (section 4) and SAt (section 5) in the future climate simulation.

\section{The Impact of Changing Transport on Insoluble Pollutants}

[14] To help understand the vertical redistribution of tropospheric COt (i.e., increases in the lower troposphere and decreases in the free troposphere), we apply a two-box model between the lower troposphere and the free troposphere. The boundary between these two boxes is defined as $500 \mathrm{hPa}$ level following Held and Soden [2006]. Mass conservation of COt in the free troposphere box suggests a balance $\mu^{F}\left(c^{L}-c^{F}\right)=m^{F} c^{F} / \tau$, in which $m^{F}$ is the total air mass within the free troposphere box, $\tau$ is the $25 \mathrm{~d}$ lifetime, $c^{L}$ and $c^{F}$ are the mean COt concentrations in the lower troposphere and the free troposphere, respectively, and $\mu^{F}$ is the mass flux exchange between the lower troposphere and the free troposphere. Assuming that the mass of the troposphere is fixed, the balance suggests $\frac{\delta \mu^{F}}{\mu^{F}}+\frac{\delta\left(c^{F}-c^{L}\right)}{c^{F}-c^{L}} \approx \frac{\delta c^{F}}{c^{F}}$. We use the simulated tracer concentration in the model and calculate the values for the second term on the left hand side, the COt concentration gradient change between the free troposphere and the lower troposphere $(+10 \%)$, and the first term on the right hand side, the relative change in the free tropospheric COt concentration $(-3 \%)$. We then calculate $\frac{\delta \mu^{F}}{\mu^{F}}$, i.e., the relative change of the mass flux exchange between these two boxes to be $-13 \%$. According to model-diagnosed tracer tendencies in the free troposphere, most $(>90 \%)$ of the transport flux change between the lower troposphere and the free troposphere comes from the advec- 


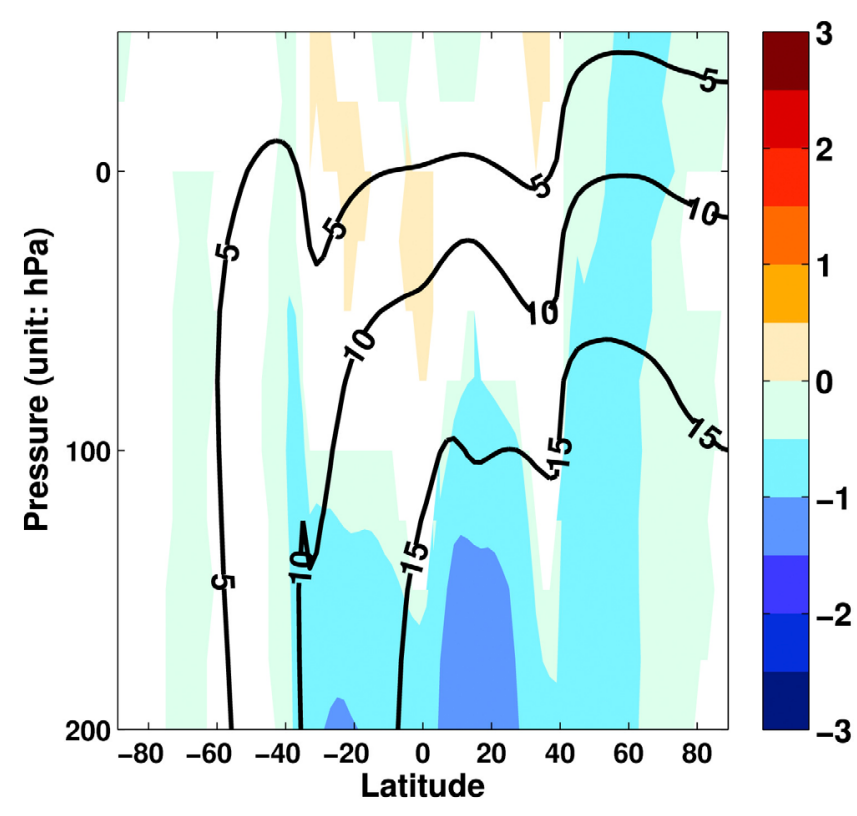

Figure 3. The 20 year average zonal mean distribution of COt tracer (unit: ppbv) during 1981-2000 (black solid contour) and the changes of COt from 1981-2000 to 20812100 (color shaded) with respect to vertical coordinates of pressure difference from the tropopause; only changes significant at 95\% confidence level assessed by $t$ test are shown.

tive tendency rather than the convective tendency. This weaker contribution from convection is consistent with the study of Holzer and Boer [2001], which shows a similar vertical redistribution of their surface-emitted tracers by only considering advection and diffusion. Applying our analysis to AM3-simulated water vapor as by Held and Soden [2006], we get a similar $14 \%$ decrease in the lower troposphere-free troposphere mass flux exchange. The mechanism by which exchange between lower troposphere and upper troposphere exchange is reduced may vary regionally. For example, over the tropics, reduced convective mass flux dominates [Held and Soden, 2006], while over midlatitudes (such as North America), the effect of weaker and less frequent cyclone activity may account for less ventilation [e.g., Wu et al., $2008 \mathrm{~b}$ ]. As our focus is on the difference between soluble and insoluble tracers, we do not probe these regional mechanisms more deeply here.

[15] Regarding the decreasing tropospheric COt concentration in the southern hemisphere in the future climate, we apply a similar two-box model, this time representing the troposphere in the northern and southern hemispheres. A $2 \%$ decrease in the hemispheric flux exchange is derived from this model. Interhemispheric transport and transport between the tropics and extratropics are dominated by the Hadley circulation [Bowman and Carrie, 2002; Bowman and Erukhimova, 2004; Hess, 2005]. Many previous studies indicate a weakened Hadley cell [e.g., Rind et al., 2001; Holzer and Boer, 2001; Held and Soden, 2006] under global warming. Consistent with these results, the AM3-simulated Hadley cell (represented by the 20 year annual mean mass stream function, see Figure S1) weakens over the lower troposphere (by less than 5\%) [Held and Soden, 2006; Vecchi and Soden, 2007], resulting in the reduced hemispheric flux exchange. ${ }^{1}$

[16] We next explore the mechanism for the strong increase of COt near the northern hemispheric midlatitude tropopause. Under global warming, the tropopause has been shown to move upward [Santer et al., 2003; Lorenz and DeWeaver, 2007]. From present day to the future, the AM3-simulated tropopause (identified as by Reichler et al. [2003], based on the World Meteorological Organization (WMO) lapse rate criterion) moves upward by $8 \mathrm{hPa}$ in the tropics and $20 \mathrm{hPa}$ over the northern high latitudes. We can plot the COt concentration relative to the tropopause (as calculated separately in the present day and future simulations) by vertically interpolating the tracer concentration (Figure 3). The enhancement of COt concentration near the tropopause is much smaller than that shown in Figure 2a, suggesting that most of the increase in COt near the tropopause in Figure 2a results from the upward movement of the tropopause.

\section{The Impact of Changing Precipitation on Soluble Pollutants}

[17] The different patterns of future changes for COt and SAt discussed in section 3 are caused by changes of precipitation (and the corresponding changes in wet deposition). The increase of SAt throughout the whole troposphere and the longer lifetime of SAt are consistent with the decrease of wet deposition $(-5 \%)$ and the resulting increase $(18 \%)$ in the lifetime against wet deposition from present day to the future. Kloster et al. [2010] also found enhanced aerosol burdens (SO4: $+4 \%$, BC: $+6 \%$, POM: $+6 \%$, associated with a $1.2 \mathrm{~K}$ global annual mean temperature increase and a $2 \%$ global mean precipitation increase) in their warmer climate (their 2030 GHG versus 2000 CONTROL simulation, both of which using identical aerosol emissions). As the total global precipitation increases in the future, the increasing SAt burden and decreasing wet deposition imply that, globally, precipitation is less effective at removing soluble tracers (SAt) in the future. In the following sections, the causes of this apparent disparity between increased precipitation and decreased wet deposition are investigated. We first briefly evaluate the AM3 model simulated precipitation and its change in 2081-2100 (section 5.1). Next, we discuss the geographical distribution of the large-scale and convective precipitation changes (section 5.2), the seasonality of the precipitation and SAt changes (section 5.3) and the possible role of changing precipitation frequency (section 5.4). In section 5.5, we propose a first step toward a simple index intended to estimate changes in the global burden and wet deposition of soluble pollutants directly from precipitation changes projected by physical climate models.

\subsection{Simulated Precipitation Under Present and Future Climates}

[18] Donner et al. [2011] have evaluated the AM3 simulated precipitation patterns and show that despite a positive bias located over the tropics by $3-5 \mathrm{~mm} \mathrm{~d}^{-1}$ and a global total precipitation excess of $16 \%$, AM3 generally well captures

\footnotetext{
${ }^{1}$ Auxiliary materials are available in the HTML. doi:10.1029/ 2011JD015642.
} 
a

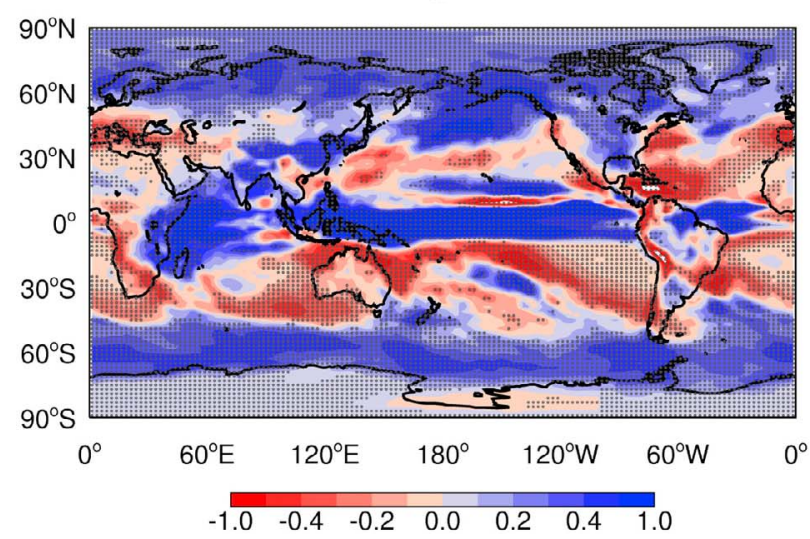

b

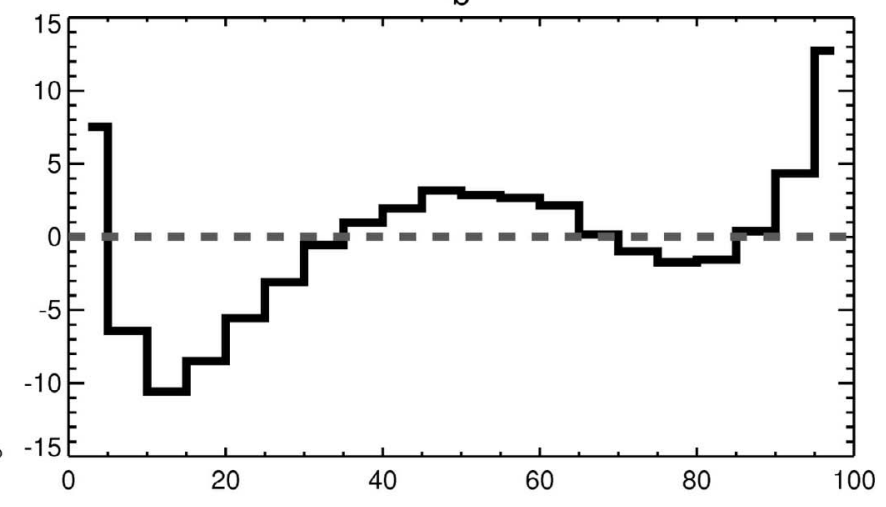

Figure 4. (a) The 20 year annual mean precipitation change from 1981-2000 to 2081-2100 (units are $\mathrm{mm} / \mathrm{d}$ ) (shaded area indicates the changes significant at the $95 \%$ confidence level assessed by $t$ test) and (b) the percentage change in the frequency of occurrence of precipitation as a function of precipitation intensity, using daily output over all land grid cells. The distribution function was calculated using 20 bins, each of which contains $5 \%$ of the total distribution for the present simulation (e.g., $0-5 \%, 5-10 \%$, etc.). The thresholds for each bin were computed for 1981-2000 and then these thresholds were applied to compute the distribution over 2081-2100.

the observed precipitation patterns reported by the Version-2 Global Precipitation Climatology Project (GPCP v.2) [Adler et al., 2003]. The total global annual precipitation increases by $6 \%$ (about $2 \% \mathrm{~K}^{-1}$ ) from $1981-2000$ to $2081-$ 2100 in the AM3 simulations, consistent with the work of Meehl et al. [2007] (5\%), Held and Soden [2006] and Vecchi and Soden [2007] $\left(2 \% \mathrm{~K}^{-1}\right)$. Strong regional precipitation changes are projected in previous studies: Emori and Brown [2005] show that annual precipitation often increases by over $20 \%$ at high latitudes, as well as in eastern Africa, central Asia and the equatorial Pacific in the IPCC AR4 model ensemble; meanwhile, substantial decreases, reaching $20 \%$, occur in the Mediterranean region [Rowell and Jones, 2006], the Caribbean region [Neelin et al., 2006] and the subtropical western coasts of each continent. In general, our simulations (Figure 4a) are consistent with these patterns, except in the Caribbean region, where AM3 predicts increased precipitation. Disagreements between models as to whether the future climate will be wetter or drier exist at the margins of climatologically wet and dry regions (e.g., in a $10^{\circ}$ band extending from latitudes centered at about $35^{\circ} \mathrm{N}$ in North America, $50^{\circ} \mathrm{N}$ in Europe, and $25^{\circ} \mathrm{N}$ in East Asia, including highly polluted areas [Held and Soden, 2006; Jacob and Winner, 2009; Christensen et al., 2007]. Therefore, the precipitation impact on soluble pollutants (such as PM) over these places may be sensitive to the regional precipitation change simulated by specific models [Jacob and Winner, 2009].

[19] In addition to the spatial pattern of precipitation, the seasonal variation of the precipitation change is also important for predicting future soluble tracer tendencies. Meehl et al. [2007] show that the monthly precipitation over North America in most models increases in January but decreases in July, consistent with our results (not shown). Their study, nevertheless, shows that models are much less consistent in their estimates of seasonal precipitation changes than in the annual mean.

[20] Donner et al. [2011] pointed out that although the AM3 simulated precipitation intensity distribution is gen- erally consistent with that observed, it fails to capture highintensity events. We next discuss precipitation events and frequency and how they change in a future climate. Following the method of Vecchi and Soden [2007], we use daily output from our model for all the land grid cells to calculate the distribution function using 20 bins, each of which contains $5 \%$ of the total distribution, with the thresholds for each bin computed using the present-day simulation. We use the same bin thresholds to compute change in the frequency of occurrence of each bin in our future simulation (Figure 4b). Extreme precipitation (precipitation above $85 \%$ quintile in the present-day simulation) occurs more frequently in the future, while moderate precipitation (5-35\% precipitation bins) occurs less frequently, in agreement with the results shown by Vecchi and Soden [2007], Meehl et al. [2007], Pall et al. [2007], and references therein. Changing precipitation frequency could potentially be an important control on wet deposition [Jacob and Winner, 2009].

[21] In the future climate, the global snow precipitation decreases by around $20 \%$ while the global total precipitation increases by $6 \%$. The scavenging factor of aerosols by snow can be much smaller than that by rain. For instance, Liu et al. [2011] assumed the in-cloud scavenging factor for black carbon aerosols in large-scale ice clouds to be $5 \%$ of that in liquid clouds based on recent observations and modeling studies. Nevertheless, in our study, we assume the same in-cloud scavenging factor for both snow and rain (section 2). Since snow accounts for less than $10 \%$ of the total precipitation and our global wet deposition is dominated by in-cloud scavenging, which we assume in our model to be independent of precipitation type, we focus hereafter on total precipitation and wet deposition changes.

\subsection{The Role of Large-Scale Versus Convective Precipitation}

[22] We examine the impacts of changing precipitation on SAt wet deposition as a way to understand the SAt burden change from present day to the future. Figure 5 shows the 

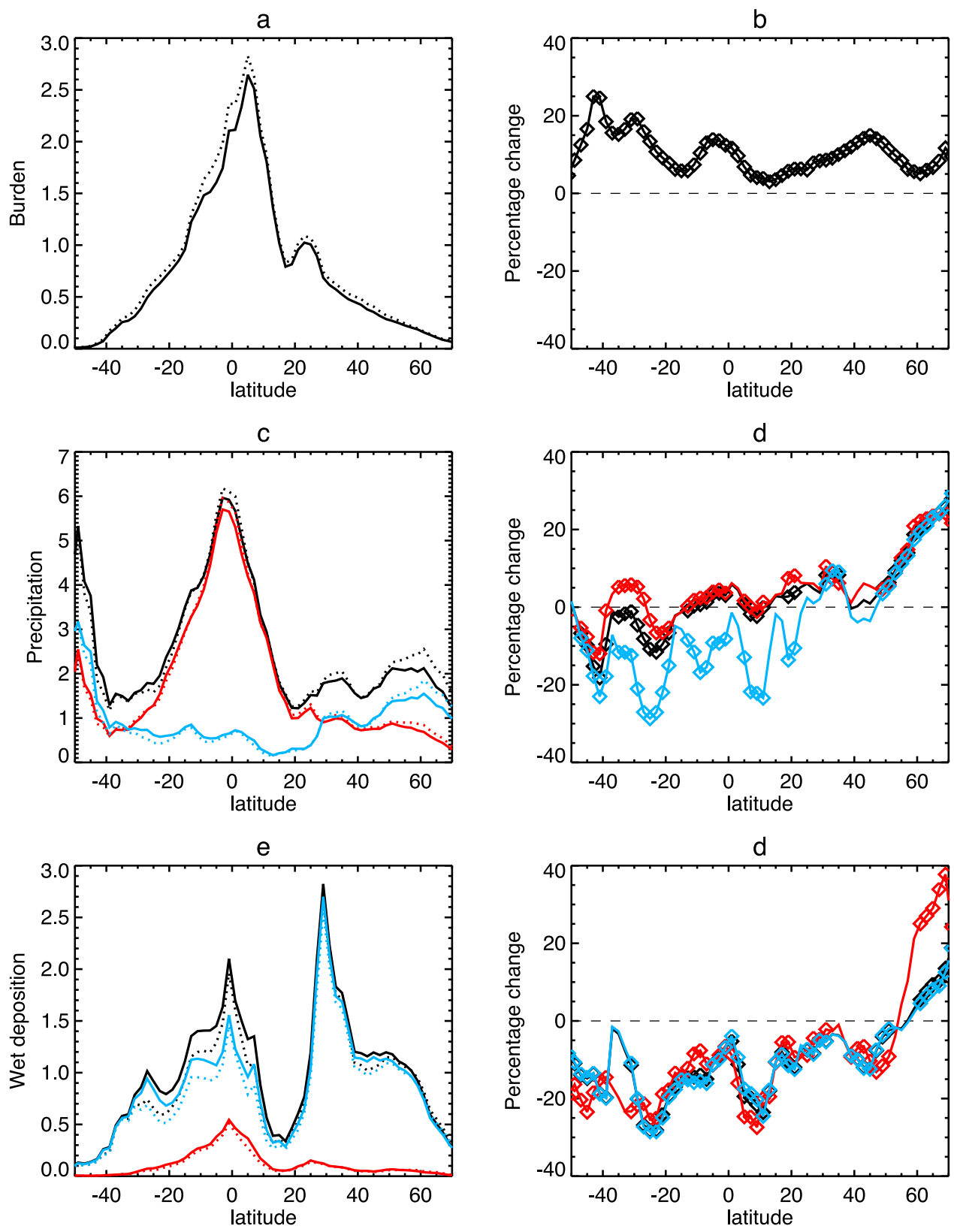

Figure 5. The 20 year annual mean latitudinal distribution of SAt burden (a) precipitation (units are $10^{-5} \mathrm{~kg} / \mathrm{m}^{2}$ ); (c) and wet deposition (units are $\mathrm{mm} / \mathrm{d}$ ); and (e) over land (units are $10^{-10} \mathrm{~kg} / \mathrm{m}^{2} / \mathrm{d}$ ): total, large-scale, and convective precipitation/wet deposition shown in black, blue, and red, respectively; solid lines and dashed lines represent 1981-2000 and 2081-2100 cases, respectively. The percentage change by 2081-2100 of the 20 year mean (b) SAt burden, (d) precipitation, and (f) SAt wet deposition calculated over each latitudinal band, as future latitudinal mean minors present-day latitudinal mean, then divided by present-day latitudinal mean. Diamonds on each line represent the signals significant at the $95 \%$ confidence level, assuming that these annual data are independent.

latitudinal distribution of the SAt burden, SAt wet deposition and precipitation over land. The present-day SAt burden peaks over the tropics with a secondary maximum at northern midlatitudes; this pattern reflects strong sources (Figure 1) and relatively longer lifetime in the tropics versus midlatitude regions (i.e., $3 \mathrm{~d}$ for SAt emitted from North America versus $9 \mathrm{~d}$ for SAt emitted from central Africa (not shown)). The total present-day precipitation is greatest in the tropics, where it is dominated by convective precipita- tion (red lines). Large-scale precipitation (blue lines) is comparable to convective precipitation in the midlatitudes. In contrast to the total precipitation, SAt wet deposition has maxima both in the tropics and in the extratropics.

[23] Wet deposition by large-scale precipitation clearly dominates the total wet deposition of the soluble SAt tracer in our model. One possibility for the different impacts of large-scale versus convective precipitation on wet deposition could be that convective precipitation tends to occur 

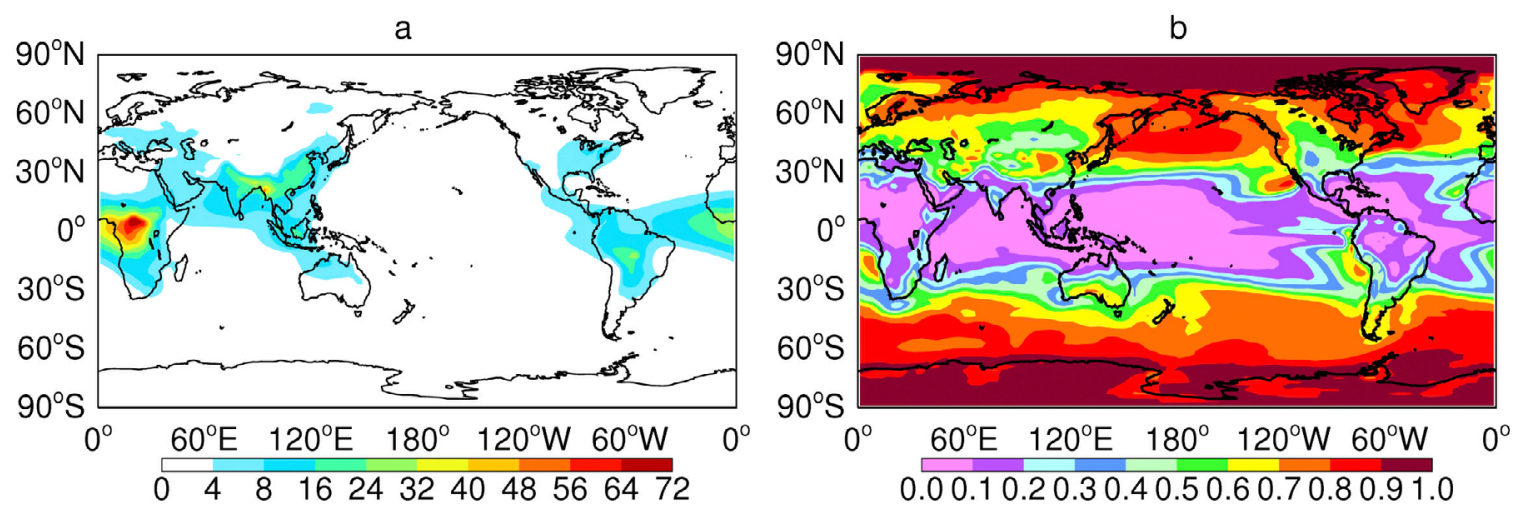

Figure 6. (a) The 20 year annual mean distribution of SAt burden during $1981-2000$ (units are $10^{-5} \mathrm{~kg} / \mathrm{m}^{2}$ ) and (b) the 20 year mean fraction of precipitation that is large scale.

over regions with lower tracer burden while large-scale precipitation dominates in more highly polluted regions. However, Figure 6 shows that over some source regions, i.e., central Africa, South Asia, East Asia, Europe and North America, convective precipitation either dominates or is comparable to that of large-scale precipitation.

[24] The balance between large-scale and convective wet deposition also depends on the parameterizations applied in the model. Our empirically chosen settings for sulfate scavenging (section 2.2) tend to make convective precipitation a more efficient scavenging process than large-scale precipitation if they occur in the same area. However, convective precipitation occurs only within subgrid updraft plumes and only washes out pollutants within those plumes (section 2.2). In contrast, the higher cloud fraction in largescale precipitation allows for more widespread scavenging of pollutants. As a result, on a regional scale, wet deposition by large-scale precipitation overwhelms that by convective precipitation (Figure 5). Our conclusion differs from that of Balkanski et al. [1993], who show a larger role for scavenging by convective precipitation $(74 \%)$ as compared to large-scale precipitation $(12 \%)$ in contributing to the global ${ }^{210} \mathrm{~Pb}$ sink in their model. The much longer lifetime (3.5 years, therefore, a more uniform distribution over the globe of $\left.{ }^{210} \mathrm{~Pb}\right)$ compared to our tracers $(25 \mathrm{~d})$ and the coarser resolution in their model $\left(4^{\circ} \times 5^{\circ}\right)$ may partly explain the difference in our findings. Textor et al. [2006] examined nine models within the AeroCom initiative (http:// dataipsl.ipsl.jussieu.fr/AEROCOM/) and found that the simulated large-scale wet deposition contributions to total wet deposition vary from 0.1 to 0.9 . The lack of model agreement results from differences in many aspects of the models, including the tracer emission used, tracer lifetime, the simulation of precipitation types, model resolutions, and wet removal parameterizations. Despite the large discrepancy in convective wet deposition over total wet deposition ratio shown by the study of Textor et al. [2006], recent studies tend to suggest a more important role from large-scale wet deposition (B. Croft et al., Aerosol processing in convective and stratiform clouds in ECHAM5-HAM, in preparation, 2010) showed a similar ratio of large-scale wet deposition $(10 \%)$ to our study when they applied a more physically detailed representation of aerosol wet scavenging by convective clouds into the ECHAM5-HAM model; (E. M. Leibensperger, personal communication, 2010) found that the global annual mean large-scale wet deposition accounts for $72 \%$ of the total sulfate aerosol deposition in the GEOS-Chem model.

[25] Noting that large-scale precipitation is more effective in washing out the SAt tracer in our model and that largescale wet deposition accounts for most of the total wet deposition, we compare the global annual large-scale precipitation change with the large-scale wet deposition change from present day to the future and find they are inconsistent ( $+6 \%$ large-scale precipitation versus $-5 \%$ large-scale wet deposition). Therefore, global precipitation changes (total, convective, or large-scale) are not good predictors for global changes in wet deposition induced by a warming climate.

[26] Total precipitation increases almost everywhere over land north of $20^{\circ} \mathrm{S}$, because of increased convective precipitation; large-scale precipitation decreases south of $20^{\circ} \mathrm{N}$ and between 40 and $50^{\circ} \mathrm{N}$ while increasing elsewhere from present day to the future (Figure $5 \mathrm{~d}$ ). The corresponding latitudinal wet deposition change follows that of the largescale wet deposition change in most latitudinal bands with a correlation coefficient above 0.9 and a root mean square difference of around $8 \%$. This implies that the latitudinal variability of the change in the large-scale precipitation can largely explain that of SAt wet deposition in a future climate. Furthermore, in a recent observational study by Lloyd [2010], a general declining tendency of sodium chloride wet deposition over the continental United States was found and was attributed to some unknown factors related to climate change. While reduced entrainment of sea salt into the atmosphere, or the changing transport of sea salt may contribute to the lower sodium chloride wet deposition, another possible explanation may be large-scale precipitation changes.

[27] While the reduction in large-scale precipitation can explain the reduced wet deposition in our simulation, one other factor may also contribute to the decrease in wet deposition. The insoluble tracer COt concentration tends to increase near the surface, and decrease in the free troposphere in the future climate (Figure 2a), possibly leading to less removal of soluble tracer because below-cloud scavenging is less efficient than in-cloud scavenging. However, we did not quantify this effect in our model.

[28] Despite the general consistency between zonal mean changes in large-scale precipitation and the SAt wet deposition (Figure 5), opposite-signed changes occur in the northern midlatitudes $\left(25-40^{\circ} \mathrm{N}\right)$, where annual wet deposition decreases but precipitation increases. Since large-scale wet 

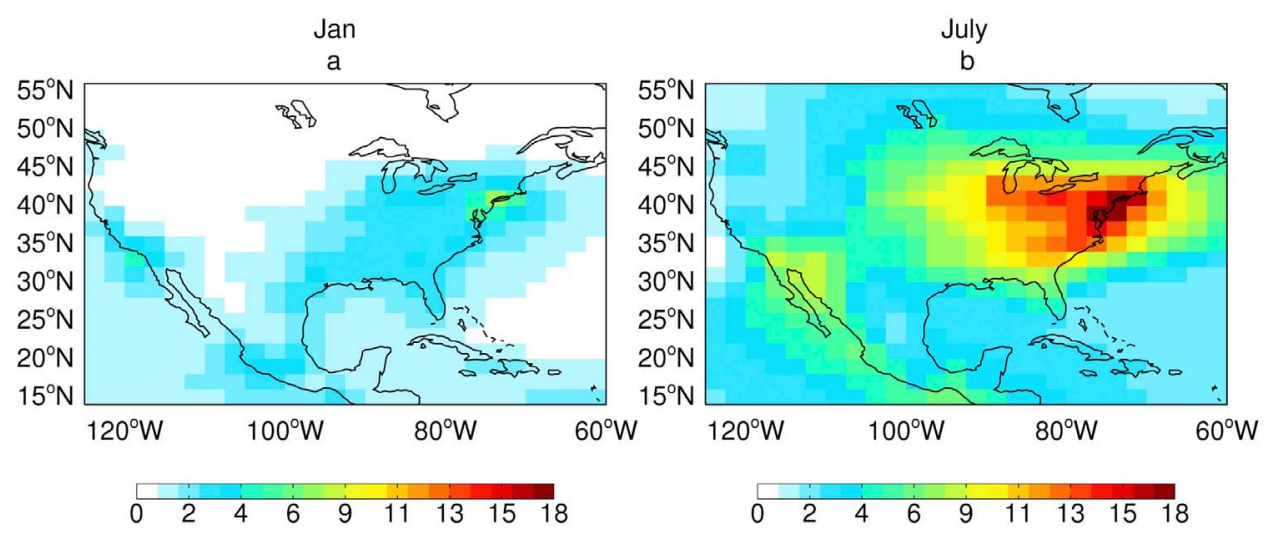

C
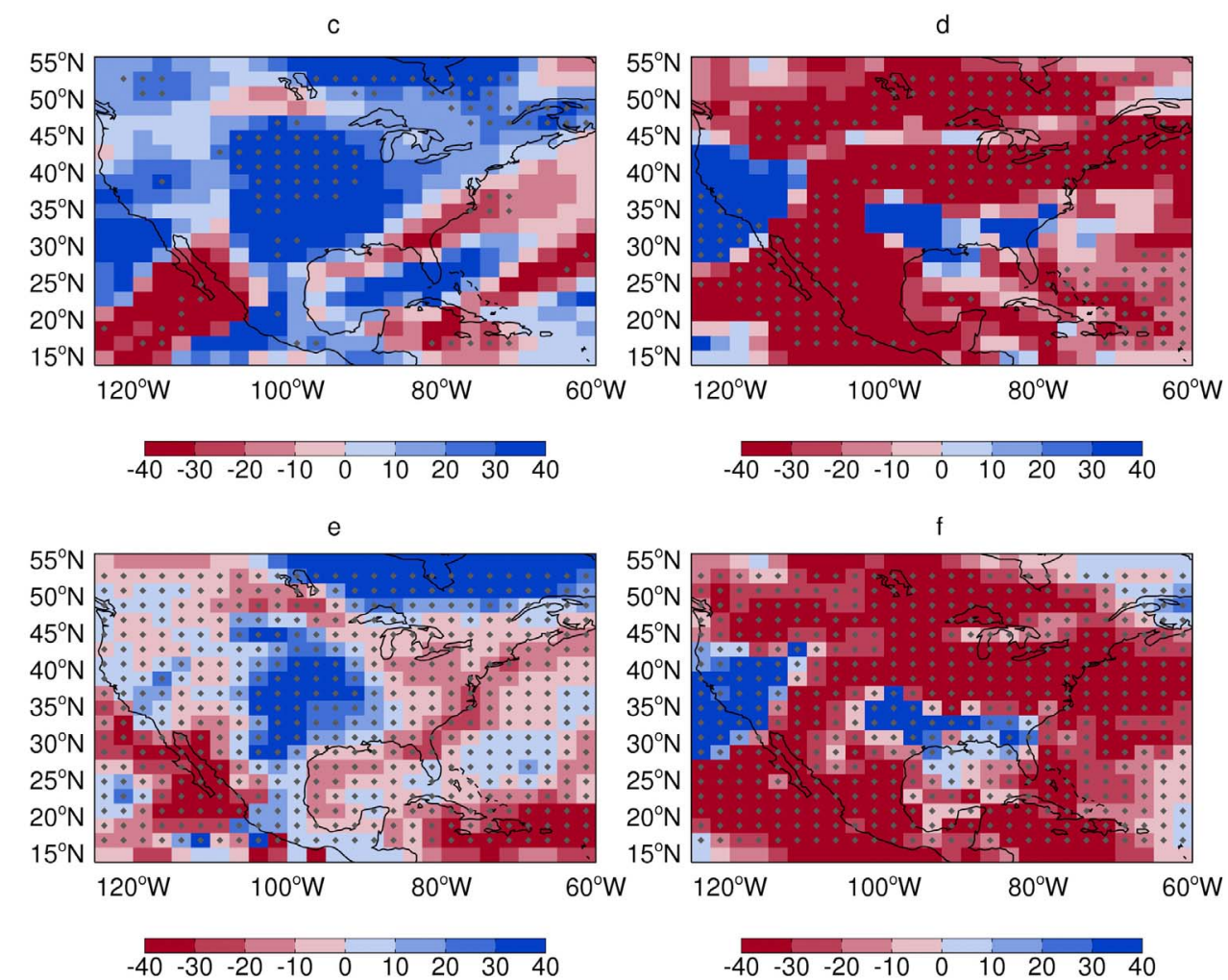

Figure 7. Twenty year mean (left) January and (right) July (a, b) SAt burden in 1981-2000 (units are $\left.10^{-5} \mathrm{~kg} / \mathrm{m}^{2}\right)$, (c, d) large-scale precipitation percentage change, and (e, f) large-scale wet deposition percentage change. Dotted area indicates changes significant at the $95 \%$ confidence level assessed by $t$ test. The maximum reduction of large-scale precipitation and wet deposition in July is about $100 \%$ and $90 \%$ while in January both are about $70 \%$.

deposition accounts for more than $90 \%$ of total wet deposition at northern midlatitudes, we focus hereafter on large-scale wet deposition.

\subsection{Seasonal Changes Over North America}

[29] The oppositely signed changes in annual wet deposition and large-scale precipitation occur over midlatitude regions, such as North America (Figure S2), where we investigate the seasonality of these changes (Figure 7). During January, the large-scale precipitation increases almost everywhere over the inland eastern and central United States, and the wet deposition increases consistently in general. Along the east coast, the large-scale precipitation and the wet deposition both decrease. In July, large-scale precipitation and wet deposition both decrease in the northern part of this region and over Mexico.

[30] Figure 8 shows the seasonal cycle of SAt burden, precipitation and wet deposition summed over all land boxes within North America. The annual mean large-scale precipitation over this region increases under global warming, driven by the precipitation increase during winter. However, during summer when the SAt burden is strongest, the lower precipitation decreases wet deposition. Consequently, the annual wet deposition drops (Figure 8). The seasonal variation of precipitation change combined with that of the SAt burden leads to the apparent disagreement between annual mean changes in precipitation and wet deposition. 
a

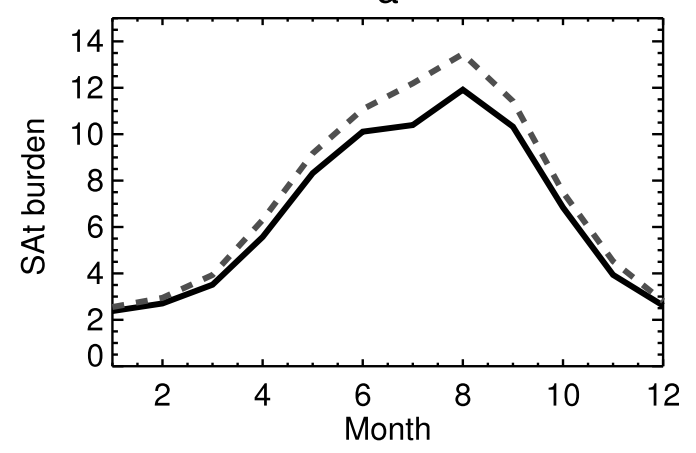

b

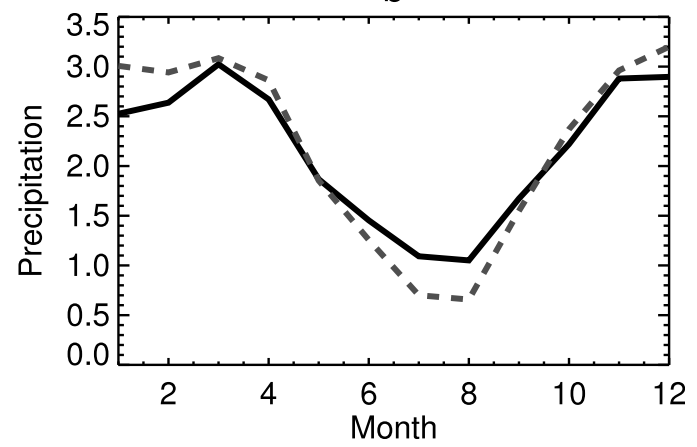

C

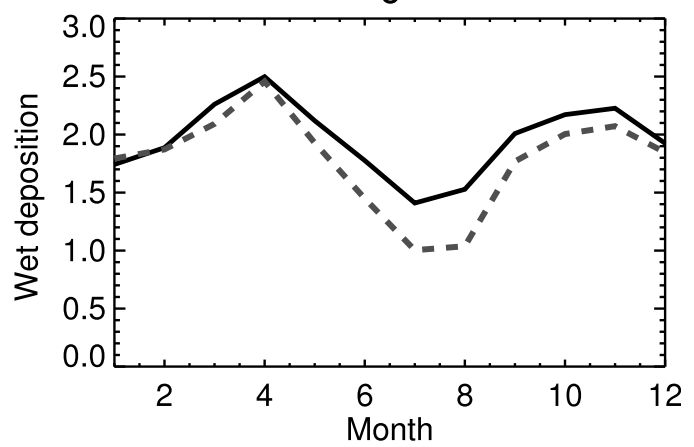

Figure 8. The 20 year mean seasonal cycle of (a) total SAt burden (units are $10^{-5} \mathrm{~kg} / \mathrm{m}^{2}$ ), (b) precipitation (units are $\mathrm{mm} / \mathrm{d}$ ), and (c) wet deposition (units are $10^{-10} \mathrm{~kg} / \mathrm{m}^{2} / \mathrm{d}$ ) over land within North America during 1981-2000 (black solid) and 2081-2100 (blue dashed).

\subsection{Changes in Precipitation Frequency Over North America}

[31] During winter, the agreement between the spatial patterns of changes in precipitation and wet deposition is weaker (Figures 7 and 8). Dawson et al. [2007] also found a weaker sensitivity in the concentration of PM in January than in July over the eastern United States when perturbing precipitation rates in their chemical transport model. Jacob and Winner [2009] argued that this sensitivity difference implies that precipitation frequency, rather than the precipitation intensity, is a dominant factor determining the wet scavenging of the soluble tracers. In this section, we evaluate the impact of precipitation frequency on wet deposition. The mean precipitation rate, $P_{r}=P_{i} \times P_{f}$, where $P_{i}$ represents the intensity of precipitation in an average pre- cipitation event and $P_{f}$ represents the frequency of such precipitation events. Changes in precipitation rate in a future climate can be explained by changes in average precipitation intensity or in precipitation frequency: $\frac{\delta P_{r}}{P_{r}}=\frac{\delta P_{i}}{P_{i}}+\frac{\delta P_{f}}{P_{f}}$. The soluble tracer burden is much lower in January than in July (Figures 7 and 8). Meanwhile, the large-scale precipitation, which is more effective in washing out the soluble tracers, is much stronger than convective precipitation in January. It is likely that in January, wet deposition in some regions is already maximized with respect to precipitation intensity during a single event (i.e., increasing precipitation intensity cannot increase wet scavenging because all of the soluble pollutant has already been washed out). Wet deposition change is thus not sensitive to $\frac{\delta P_{i}}{P_{i}}$ (and as a result, it is not consistent with $\left.\frac{\delta P_{r}}{P_{r}}\right)$. Instead, the precipitation frequency change $\left(\frac{\delta P_{f}}{P_{f}}\right)$ plays a more important role. We count the number of January days with precipitation within 1981-2000 and 2081-2100 separately to represent daily precipitation frequency. Figure 9a shows that the number of precipitation days during January over the United States changes from present day to the future by a few percent (decreasing in the eastern coastal United States and the Great Lakes while increasing in the southern and western United States). The relative change of precipitation frequency is generally much smaller than that of precipitation intensity change (Figure 9b, calculated as $\left.\frac{\delta P_{i}}{P_{i}}=\frac{\delta P_{r}}{P_{r}}+\frac{\delta P_{f}}{P_{f}}\right)$. As mentioned in section 5.3, in January, the wet deposition change is generally consistent with the precipitation rate change, especially over the central United States (Figure 7). However, over the Great Lakes, Maine, Southern Canada and New Brunswick, Canada, wet deposition decreases while the precipitation rate increases (Figure 7). The decrease in wet deposition is driven by a decrease of precipitation frequency (Figure 9a) and occurs despite an increase in precipitation intensity (Figure 9b). The spatial correlation coefficient between the relative change of precipitation intensity and wet deposition in January is 0.2 while between that of precipitation frequency and the wet deposition is 0.6 over the United States. Wet deposition is apparently not sensitive in the model to the precipitation intensity over this area, therefore the increase in precipitation intensity does not lead to increased wet deposition. However, over most regions such as south of $30^{\circ} \mathrm{N}$ (Figure 7), changing precipitation intensity plays a major role.

[32] Examining the percentage change in the number of precipitation days globally for 20 Januarys, we find reductions over most tropical and midlatitude regions (Figure S3). But the change is usually small (within 5\%) except over the Middle East, Arabia and West Africa (where the reduction can be above $30 \%$ ) compared to that of wet deposition (typically above $10 \%$ ), suggesting precipitation frequency typically plays a minor role in determining the change of wet deposition. Similar decreases in precipitation frequency occur when we analyze the entire 20 year daily precipitation data rather than focusing on January (not shown). The reduction of precipitation days and the increase of global precipitation are consistent with the increases of precipitation intensity in a warming climate (se the work of Meehl et al. [2007] and Figure 4b).

[33] The scavenging coefficients used in AM3 are independent of the size of rain droplets. However, intense rain is 

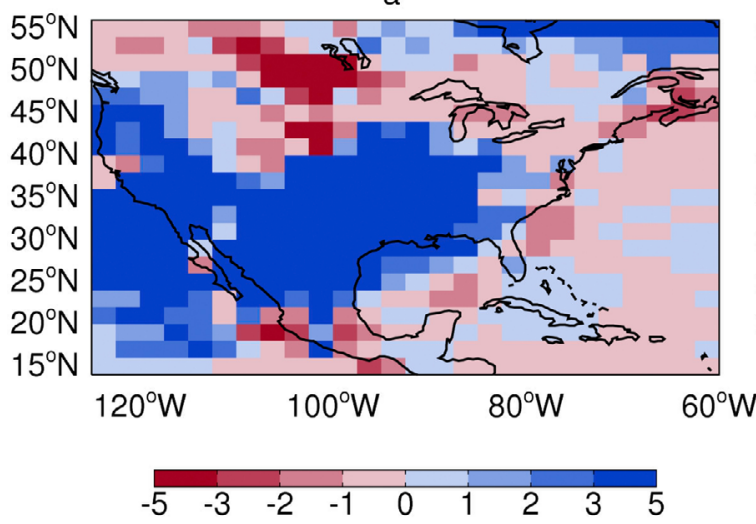

$\mathrm{b}$

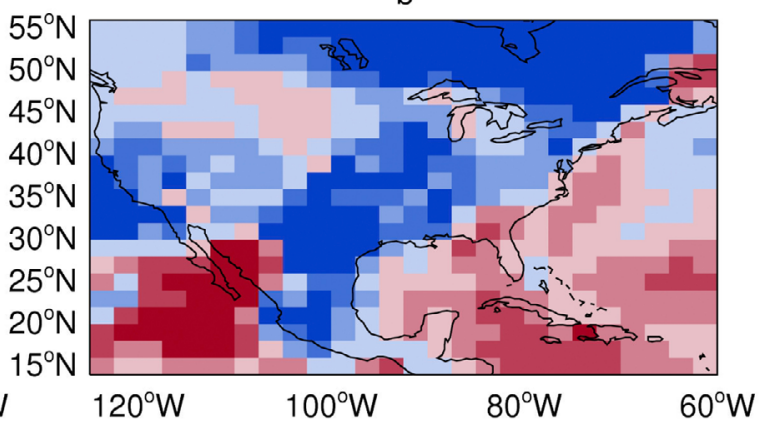

$\begin{array}{lllllllll}-40 & -30 & -20 & -10 & 0 & 10 & 20 & 30 & 40\end{array}$

Figure 9. Percentage change of (a) the number of days with large-scale precipitation in all Januarys and (b) the large-scale precipitation intensity (calculated as the difference between the relative changes in large-scale precipitation (Figure 7c) and precipitation frequency (Figure 9a)) in January from 19812000 to 2081-2100 (units are \%); note different color scales.

usually associated with larger droplets, implying that the scavenging coefficient should increase for larger rain rates [Croft et al., 2009; Tost et al., 2007; Seinfeld and Pandis, 2006]. Therefore, changes in precipitation intensity, or the rain rate as the product of intensity and frequency may have a stronger impact than that deduced from our study. We did not consider the length of dry spells between precipitation (and wet removal) events, which should also affect the accumulation of pollutants and drive differences in wet deposition.

\subsection{The Diagnosed Precipitation Impact Index}

[34] We show in previous sections that the spatial and temporal patterns of large-scale precipitation changes and that of the SAt burden largely determine the impact of precipitation changes on the future SAt distribution. We seek here to develop a simple index to enable an estimate of changes in surface soluble pollutants directly from precipitation fields simulated with physical climate models. As a first step, we test here whether we can infer the future changes in the SAt wet deposition and burden as simulated with GFDL AM3 directly from the present-day tracer and precipitation distributions as well as the simulated precipitation changes from the present to the future. We focus on annual means, because climate models are more consistent on annual mean precipitation change simulations [Meehl et al., 2007] and there is an annual formulation of the U.S. Environmental Protection Agency (EPA)'s National Ambient Air Quality Standard (NAAQS) for $\mathrm{PM}_{2.5}$ (http://www.epa.gov/ air/criteria.html).

[35] The wet deposition flux is directly proportional to the local concentration, and depends nonlinearly on the local precipitation production (section 2.1), particularly largescale precipitation (as demonstrated in section 5.2). If we assume that the main climate change influence on soluble pollutants occurs primarily through precipitation (the spatial distribution of the burden change because of transport is small as demonstrated in Figure 2), we can examine the possibility of using the large-scale precipitation weighted by present-day SAt tracer burden to directly infer the future SAt wet deposition change. Although the wet deposition change over each grid box is affected by many processes other than local wet deposition (most notably, transport), the spatial pattern of changes in the wet deposition is well correlated with that of the burden-weighted large-scale precipitation change (the correlation coefficients for the global spatial patterns are 0.6, Figure 10).

[36] On the basis of the correlation shown above, we define the diagnosed precipitation impact index (DPI) to be: $D P I=\frac{\overline{B \cdot \Delta P_{l s}}}{\bar{B} P_{l s}}$, where B represents the present-day SAt burden, $\Delta P_{l s}$ and $P_{l s}$ represents the change in large-scale precipitation and the present-day large-scale precipitation and the overbar represents a spatial average. This DPI is consistent in sign with simulated relative changes in global wet deposition annually $(-6 \%$, within a factor of $50 \%$ of the corresponding annual relative changes in wet deposition, $-9 \%$ ). Thus this DPI index may be useful to predict the sign of future changes in the global SAt wet deposition and burden directly from a present-day distribution of SAt burden and large-scale precipitation as well as simulated large-scale precipitation changes. The DPI index can be used only under two key assumptions that are valid in the AM3 model on a global annual mean basis: 1. large-scale precipitation dominated wet deposition and 2. precipitation frequency changes are unimportant.

[37] We test the generality of this approach by applying it to another soluble pollutant tracer (SAt12), with the same sources as SAt, but with a $12 \mathrm{~d}$ lifetime. The shorter lifetime restricts the tracer distribution to near the source regions. The DPI approach also works for SAt12. For example, the DPI calculated for SAt12 is also negative $(-10 \%)$ and it is consistent with decreasing SAt12 wet deposition (-9\%) in a future climate. Therefore, the DPI approach for predicting the impact of precipitation change is also applicable to soluble species with shorter lifetimes. Tracers with longer lifetimes require further study as transport might play a greater role and limit the utility of the DPI approach.

[38] The DPI index provides a simple way to examine the precipitation impact on soluble pollutant distributions by using only precipitation fields from different climate models. However, the relative importance of large-scale versus convective wet deposition is highly inconsistent across models 


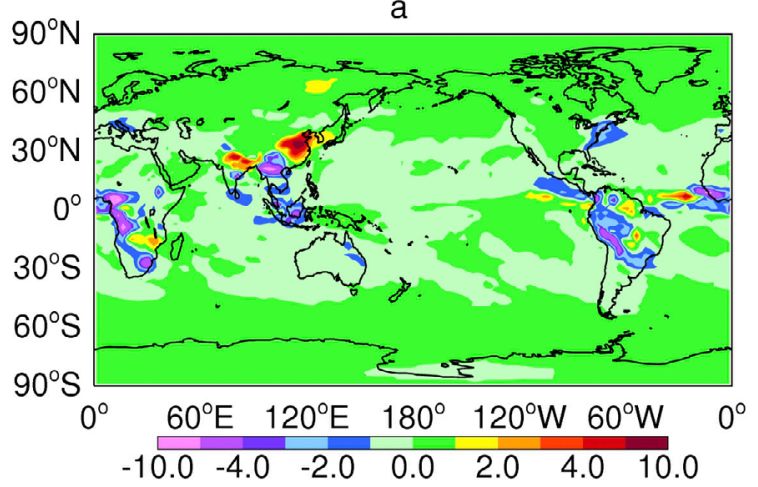

b

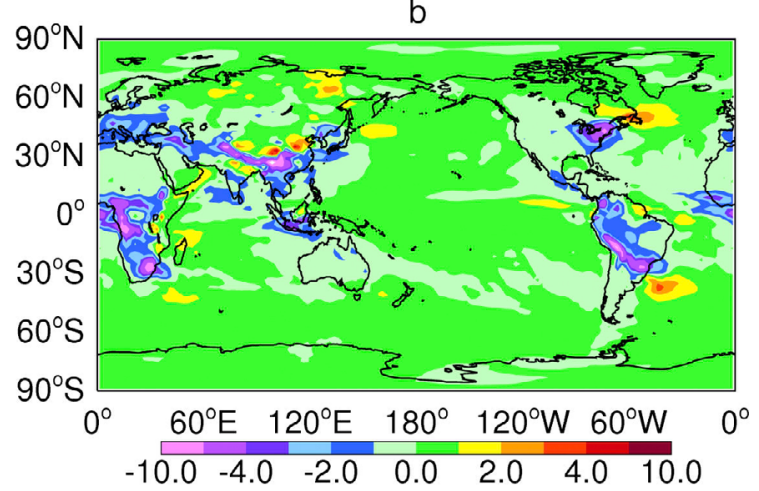

Figure 10. The 20 year annual mean (a) diagnosed precipitation impact (units are $10^{-5} \mathrm{~kg} / \mathrm{m}^{2} * \mathrm{~kg} / \mathrm{m}^{2} / \mathrm{d}$ ) and (b) wet deposition change (units are $10^{-6} \mathrm{~kg} / \mathrm{m}^{2} / \mathrm{d}$ ).

[e.g., Textor et al., 2006]. Clearly, the DPI calculated using the large-scale precipitation changes would not be relevant for a model in which convective precipitation dominates wet deposition. Improved understanding and parameterizations of wet deposition processes would allow for the development of a more broadly applicable DPI, which should further help to improve confidence in projecting impacts of precipitation changes on wet deposition of soluble pollutants.

\section{Conclusions}

[39] We have used the Atmospheric Model version 3 (AM3) [Donner et al., 2011] developed by the Geophysical Fluid Dynamics Laboratory (GFDL) to investigate how changes in climate may drive pollutant distributions to change in a warmer climate. In order to isolate climateinduced transport and precipitation changes and their implications for atmospheric pollutant distributions, we incorporate a simple carbon monoxide-like $(\mathrm{CO})$ tracer $(\mathrm{COt})$, with $\mathrm{CO}$ emissions and a fixed $25 \mathrm{~d}$ lifetime, and a soluble version of that tracer (SAt) in the model for 1981-2000 and 2081-2100 meteorological conditions.

[40] From a global and hemispheric perspective, a warming climate affects pollution transport more in the vertical than in the horizontal (the interhemispheric exchange decreases by only $2 \%$ but the mass exchange between the lower troposphere and the free troposphere decreases by 13\%). Both surface COt and SAt concentrations increase (less than 5\% and about $10 \%$, respectively) near source regions, because of reduced boundary layer ventilation and reduced wet deposition in a future climate. These results support prior emphasis on the need for tighter emission regulations to achieve a desired level of air quality as climate warms [e.g., Holzer and Boer, 2001; Wu et al., 2008b]. A higher tropopause ( $8 \mathrm{hPa}$ in the tropics and $20 \mathrm{hPa}$ in the high latitudes) may lead to stronger forcing from radiatively active pollutants.

[41] In this model, large-scale precipitation dominates the wet scavenging of soluble pollutants, even in the tropics where convective precipitation exceeds large-scale precipitation. For this model, one therefore cannot use changes in total convective precipitation as a predictive index for the sign of the changes in soluble tracer in a warmer climate. Furthermore, we find that the global large-scale precipitation changes are not a good indicator. Instead, the latitudinal wet deposition change largely follows the regional pattern of large-scale precipitation (correlation coefficient for zonal annual mean large-scale precipitation and tracer wet deposition change is above 0.9 ). We conclude that as climate warms, the longer lifetime of soluble pollutants with respect to wet deposition is mostly due to the simulated decrease in the large-scale precipitation over land.

[42] The seasonality of precipitation changes also modulates its impact. For example, over North America, precipitation and wet deposition both increase in January, and decrease in July. The absolute magnitude of the precipitation change is greater in January, so annual precipitation increases; the absolute magnitude of the wet deposition change is greater in July, so annual mean wet deposition decreases. The agreement between the precipitation and wet deposition changes over North America is weaker in January than in July, implying a possible role for changing precipitation frequency in determining tracer wet removal in winter, as shown to occur over the Great Lakes. However, precipitation frequency declines only weakly (less than 10\%) in most regions and seasons in the model, only weakly contributing to the changes in wet deposition in most cases.

[43] Although the GFDL AM3 model includes aerosolcloud interactions, we have not assessed here the importance of these interactions in contributing to the simulated changes in the soluble tracer distribution. Recent studies show the aerosol-cloud effect tends to vary with cloud type, increasing convective precipitation and decreasing stratiform precipitation [Lee and Feingold., 2010; Small et al., 2009]. These results suggest that increased soluble aerosol concentration in a future climate will decrease large-scale precipitation, potentially reducing wet deposition and increasing aerosol lifetime. For sulfate aerosols, an increased lifetime may enhance their cooling impact on climate while an increased lifetime for black carbon may result in a stronger warming effect.

[44] As wet deposition changes dominate the changes in soluble pollutant distribution from 1981-2000 to 20812100 (as opposed to a transport-driven redistribution), we explore the possibility of using SAt burden-weighted largescale precipitation change to help evaluate the precipitation impact on soluble tracer burden in a future climate. We find that SAt burden-weighted large-scale precipitation annual mean changes have a fairly good spatial correlation with the SAt wet deposition change in the future climate $(\mathrm{r}=0.6)$. We thus develop a diagnosed precipitation impact (DPI) 
index (the global mean of present-day pollutant burden weighted large-scale precipitation changes (future-present) divided by the global mean of present-day pollutant weighted large-scale precipitation) to directly infer the soluble pollutant wet deposition responses from changes in precipitation as simulated by a climate model. This index captures the sign and magnitude (within 50\%) of the relative changes in the global wet deposition of the soluble pollutant tracer. If our findings that large-scale precipitation dominates wet deposition and that horizontal pattern transport patterns change little in a future climate are broadly applicable, the DPI could be applied to large-scale precipitation fields in other climate models to obtain an estimate of the distribution of soluble pollutants in future scenarios.

[45] The robustness of any projections of future soluble pollutant tendencies should be evaluated with an ensemble of models. Climate models, however, are notoriously inconsistent in their simulated seasonal and regional precipitation changes [Christensen et al., 2007]. Applying our diagnosed precipitation impact index to other models that have precipitation change patterns available provides us a simple yet quantitative way to estimate the impact of precipitation changes on soluble tracers in a warmer climate. Such an approach, however, requires our finding that large-scale precipitation dominates wet deposition to be broadly applicable. Given the discrepancy in large-scale versus convective precipitation simulations across climate models and their relative importance in determining wet deposition [Textor et al., 2006], there is a critical need for observational studies to advance our understanding of these processes and improve their representation in models.

[46] Acknowledgments. The authors would like to thank the Task Force of Hemispheric Transport of Atmospheric Pollutant, specifically Martin Schultz and Oliver Wild for putting together the HTAP TP1x emissions and designing the tracer experiments. The authors also want to acknowledge Leo Donner, Junfeng Liu, and Yi Ming for helpful discussions.

\section{References}

Adler, R. F., et al. (2003), The Version-2 Global Precipitation Climatology Project (GPCP) monthly precipitation analysis (1979-present), J. Hydrometeorol., 4, 1147-1167, doi:10.1175/1525-7541(2003)004< 1147:TVGPCP $>2.0 . \mathrm{CO} ; 2$.

Austin, J., and R. J. Wilson (2006), Ensemble simulations of the decline and recovery of stratospheric ozone, J. Geophys. Res., 111, D16314, doi:10.1029/2005JD006907.

Avise, J., et al. (2009), Attribution of projected changes in summertime US ozone and $\mathrm{PM}_{2.5}$ concentrations to global changes, Atmos. Chem. Phys., 9, 1111-1124, doi:10.5194/acp-9-1111-2009.

Balkanski, Y. J., D. J. Jacob, G. M. Gardner, W. Graustein, and K. Turekian (1993), Transport and residence times of tropospheric aerosols inferred from a global three-dimensional simulation of ${ }^{210} \mathrm{~Pb}, J$. Geophys. Res., 98(D11), 20,573-20,586.

Bowman, K. P., and G. D. Carrie (2002), The mean-meridional transport circulation of the troposphere in an idealized GCM, J. Atmos. Sci., 59(9), 1502-1514, doi:10.1175/1520-0469(2002)059<1502:TMMTCO >2.0. $\mathrm{CO} ; 2$.

Bowman, K. P., and T. Erukhimova (2004), Comparison of global-scale Lagrangian transport properties of the NCEP reanalysis and CCM3, J. Clim., 17(5), 1135-1146, doi:10.1175/1520-0442(2004)017<1135: COGLTP $>2.0 . \mathrm{CO} ; 2$.

Christensen, J. H., et al. (2007), Regional climate projections, in Climate Change 2007: The Physical Science Basis. Contribution of Working Group I to the Fourth Assessment Report of the Intergovernmental Panel on Climate Change, edited by S. Solomon et al., pp. 847-940, Cambridge Univ. Press, Cambridge, U. K.

Croft, B., U. Lohmann, R. V. Martin, P. Stier, S. Wurzler, J. Feichter, R. Posselt, and S. Ferrachat (2009), Aerosol size-dependent below-cloud scavenging by rain and snow in the ECHAM5-HAM, Atmos. Chem. Phys., 9, 4653-4675, doi:10.5194/acp-9-4653-2009.

Dawson, J. P., P.J. Adams, S.N Pandis. (2007), Sensitivity of PM2.5 to climate in the eastern US: A modeling case study, Atmos. Chem. Phys., 7, 4295-4309.

Delworth, T. L., et al. (2006), GFDL's CM2 global coupled climate models. Part I: Formulation and simulation characteristics, J. Clim., 19, 643-674, doi:10.1175/JCLI3629.1.

Denman, K. L., et al. (2007), Couplings between changes in the climate system and biogeochemistry, in Climate Change 2007: The Physical Science Basis. Contribution of Working Group I to the Fourth Assessment Report of the Intergovernmental Panel on Climate Change, edited by S. Solomon et al., pp. 499-588, Cambridge Univ. Press, Cambridge, U. K.

Donner, L., et al. (2011), The dynamical core, physical parameterizations, and basic simulation characteristics of the atmospheric component AM3 of the GFDL global coupled model CM3, J. Clim., 24, 3484-3519, doi:10.1175/2011JCLI3955.1

Emori, S., and S. J. Brown (2005), Dynamic and thermodynamic changes in mean and extreme precipitation under changed climate, Geophys. Res. Lett., 32, L17706, doi:10.1029/2005GL023272.

Giorgi, F., and W. L. Chameides (1985), The rainout parameterization in a photochemical model, J. Geophys. Res., 90(D5), 7872-7880, doi:10.1029/JD090iD05p07872.

Gordon, H. B., et al. (2002), The CSIRO Mk3 Climate System Model, Tech. Rep. 60, CSIRO Atmos. Res., Aspendale, Victoria, Australia.

Gualdi, S., et al. (2006), The main features of the 20th century climate as simulated with the SGX coupled GCM, Claris News, 4, 7-13.

Held, I. M., and B. J. Soden (2006), Robust response of the hydrological cycle to global warming, J. Clim., 19, 5686-5699, doi:10.1175/JCLI3990.1.

Hess, P. G. (2005), A comparison of two paradigms: The relative global roles of moist convective versus nonconvective transport, J. Geophys. Res., 110, D20302, doi:10.1029/2004JD005456.

Holzer, M., and G. J. Boer (2001), Simulated changes in atmospheric transport climate, J. Clim., 14, 4398-4420, doi:10.1175/1520-0442(2001) $014<4398$ :SCIATC $>2.0 . \mathrm{CO} ; 2$.

Horowitz, L. W., et al. (2003), A global simulation of tropospheric ozone and related tracers: Description and evaluation of MOZART, version 2, J. Geophys. Res., 108 (D24), 4784, doi:10.1029/2002JD002853.

Jacob, D. J., and D. A. Winner (2009), Effect of climate change on air quality, Atmos. Environ., 43, 51-63, doi:10.1016/j.atmosenv.2008.09.051.

Kloster, S., F. Dentener, J. Feichter, F. Raes, U. Lohmann, E. Roeckner, and I. Fischer-Bruns (2010), A GCM study of future climate response to aerosol pollution reduction, Clim. Dyn., 34, 1117-1194, doi: $10.1007 / \mathrm{s} 00382-009-0537-0$.

Lee, S. S., and G. Feingold (2010), Precipitating cloud-system response to aerosol perturbations, Geophys. Res. Lett., 37, L23806, doi:10.1029/ 2010GL045596.

Li, F., P. Ginoux, and V. Ramaswamy (2008), Distribution, transport, and deposition of mineral dust in the Southern Ocean and Antarctica: Contribution of major sources, J. Geophys. Res., 113, D10207, doi:10.1029/ 2007JD009190.

Lin, J.-T., K. O. Patten, K. Hayhoe, X.-Z. Liang, D. J. Wuebbles (2008), Effects of future climate and biogenic emissions changes on surface ozone over the United States and China, J. Appl. Meteorol. Climatol., 47, 1888-1909, doi:10.1175/2007JAMC1681.1.

Liu, J., S. Fan, L. W. Horowitz, and H. Levy II (2011), Evaluation of factors controlling long-range transport of black carbon to the Arctic, J. Geophys. Res., 116, D04307, doi:10.1029/2010JD015145.

Lloyd, P. J. (2010), Changes in the wet precipitation of sodium and chloride over the continental United States, 1984-2006, Atmos. Environ., 44, 3196-3206, doi:10.1016/j.atmosenv.2010.05.016.

Lorenz, D. J., and E. T. DeWeaver (2007), Tropopause height and zonal wind response to global warming in the IPCC scenario integrations, J. Geophys. Res., 112, D10119, doi:10.1029/2006JD008087.

Meehl, G. A., et al. (2007), Global climate projections, in Climate Change 2007: The Physical Science Basis. Contribution of Working Group I to the Fourth Assessment Report of the Intergovernmental Panel on Climate Change, edited by S. Solomon et al., pp. 747-846, Cambridge Univ. Press, Cambridge, U. K.

Mickley, L. J., et al. (2004), Effects of future climate change on regional air pollution episodes in the United States, Geophys. Res. Lett., 31, L24103, doi:10.1029/2004GL021216.

Neelin, J. D., M. Münnich, H. Su, J. E. Meyerson, and C. E. Holloway (2006), Tropical drying trends in global warming models and observations, Proc. Natl. Acad. Sci. U. S. A., 103, 6110-6115, doi:10.1073/ pnas. 0601798103

Nolte, C. G., A. B. Gilliland, C. Hogrefe, and L. J. Mickley (2008), Linking global to regional models to assess future climate impacts on surface 
ozone levels in the United States, J. Geophys. Res., 113, D14307, doi:10.1029/2007JD008497.

Pall, P., M. R. Allen, and D. A. Stone (2007), Testing the ClausiusClapeyron constraint on changes in extreme precipitation under $\mathrm{CO}_{2}$ warming, Clim. Dyn., 28, 351-363, doi:10.1007/s00382-006-0180-2.

Putman, W. M., and S.-J. Lin (2007), Finite-volume transport on various cubed-sphere grid, J. Comput. Phys., 227, 55-78, doi:10.1016/j. jcp.2007.07.022.

Pye, H. O. T., H. Liao, S. Wu, L. J. Mickley, D. J. Jacob, D. K. Henze, and J. H. Seinfeld (2009), Effects of changes in climate and emissions on future sulfate-nitrate-ammonium aerosol levels in the United States, J. Geophys. Res., 114, D01205, doi:10.1029/2008JD010701.

Racherla, P. N., and P. J. Adams (2006), Sensitivity of global tropospheric ozone and fine particulate matter concentrations to climate change, J. Geophys. Res., 111, D24103, doi:10.1029/2005JD006939.

Reichler, T., M. Dameris, and R. Sausen (2003), Determining the tropopause height from gridded data, Geophys. Res. Lett., 30(20), 2042, doi:10.1029/ 2003GL018240.

Rind, D., J. Lerner, and C. McLinden (2001), Changes of tracer distributions in the doubled $\mathrm{CO}_{2}$ climate, J. Geophys. Res., 106(D22), 28,061-28,079.

Rowell, D. P., and R. G. Jones (2006), Causes and uncertainty of future summer drying over Europe, Clim. Dyn., 27, 281-299, doi:10.1007/ s00382-006-0125-9.q

Santer, B. D., et al. (2003), Behavior of tropopause height and atmospheric temperature in models, reanalyses, and observations: Decadal changes, J. Geophys. Res., 108(D1), 4002, doi:10.1029/2002JD002258.

Schultz, M., and S. Rast (2007), RETRO report on emission data sets and methodologies for estimating emissions, work package 1 , deliverable D1-6, EU-Contract EVK2-CT-2002-00170, Max Planck Inst. for Meteorol., Hamburg, Germany. [Available at http://retro.enes.org/reports/ D1-6 final.pdf.]

Seinfeld, J. H., and S. N. Pandis (2006), Atmospheric Chemistry and Physics, Wiley, New York.

Small, J. D., P. Y. Chuang, G. Feingold, and H. Jiang (2009), Can aerosol decrease cloud lifetime?, Geophys. Res. Lett., 36, L16806, doi:10.1029/ 2009GL038888.

Tagaris, E., K. Manomaiphiboon, K.-J. Liao, L. R. Leung, J.-H. Woo, S. He, P. Amar, and A. G. Russell (2007), Impacts of global climate change and emissions on regional ozone and fine particulate matter concentrations over the United States, J. Geophys. Res., 112, D14312, doi:10.1029/ 2006JD008262.

Textor, C., et al. (2006), Analysis and quantification of the diversities of aerosol life cycles within AeroCom, Atmos. Chem. Phys., 6, 1777-1813, doi:10.5194/acp-6-1777-2006.

Tost, H., P. Jöckel, A. Kerkweg, A. Pozzer, R. Sander, and J. Lelieveld (2007), Global cloud and precipitation chemistry and wet deposition: Tropospheric model simulations with ECHAM5/MESSy1, Atmos. Chem. Phys., 7, 2733-2757, doi:10.5194/acp-7-2733-2007.

van der Werf, G. R., J. T. Randerson, L. Giglio, G. J. Collatz, P. S. Kasibhatla, and A. F. Arellano Jr. (2006), Interannual variability in global biomass burning emissions from 1997 to 2004, Atmos. Chem. Phys., 6, 3423-3441, doi:10.5194/acp-6-3423-2006.

Vecchi, G. A., and B. J. Soden (2007), Global warming and the weakening of the tropical circulation, J. Clim., 20, 4316-4340, doi:10.1175/JCLI4258.1.

Weaver, C. P., et al. (2009), A preliminary synthesis of modeled climate change impacts on U.S. regional ozone concentrations, Bull. Am. Meteorol. Soc., 90, 1843-1863, doi:10.1175/2009BAMS2568.1.

Wu, S., et al. (2008a), Effects of 2000-2050 changes in climate and emissions on global tropospheric ozone and the policy-relevant background ozone in the United States, J. Geophys. Res., 113, D18312, doi:10.1029/2007JD009639.

Wu, S., et al. (2008b), Effects of 2000-2050 global change on ozone air quality in the United States, J. Geophys. Res., 113, D06302, doi:10.1029 2007JD008917.

G. Chen, Department of Earth and Atmospheric Sciences, Cornell University, Ithaca, NY 14853, USA.

Y. Fang, Atmospheric and Oceanic Sciences Program, Princeton University, Princeton, NJ 08540, USA. (yfang@princeton.edu)

A. M. Fiore, I. Held, L. W. Horowitz, H. Levy, and G. Vecchi, Geophysical Fluid Dynamics Laboratory, National Oceanic and Atmospheric Administration, PO Box 308, 201 Forrestal Rd., Princeton, NJ 08542-0308, USA.

A. Gnanadesikan, Department of Earth and Planetary Science, Johns Hopkins University, 327 Olin Hall, 3400 N. Charles St., Baltimore, MD 21218, USA. 